\title{
Cooperativity and Avidity in Membrane Binding by C2AB Tandem Domains of Synaptotagmins 1 and 7
}

H. Tran, L. Anderson, and J. Knight

Running title: Cooperativity in $\mathrm{C} 2 \mathrm{AB}$ membrane binding 


\begin{abstract}
Synaptotagmin-1 (Syt-1) and synaptotagmin-7 (Syt-7) contain analogous tandem C2 domains, $\mathrm{C} 2 \mathrm{~A}$ and $\mathrm{C} 2 \mathrm{~B}$, which together serve as a $\mathrm{Ca}^{2+}$ sensor to bind membranes and promote the stabilization of exocytotic fusion pores. Functionally, Syt-1 triggers fast release of neurotransmitters, while Syt-7 is involved in lower- $\mathrm{Ca}^{2+}$ processes such as hormone secretion. Evidence suggests that Syt-1 C2 domains bind membranes cooperatively, penetrating farther into membranes as the $\mathrm{C} 2 \mathrm{AB}$ tandem than as individual $\mathrm{C} 2$ domains. In contrast, we previously reported that the two $\mathrm{C} 2$ domains of Syt-7 bind membranes independently, based in part on measurements of their liposome dissociation kinetics. Here, we have investigated the effects of C2A-C2B interdomain cooperativity with Syt-1 and Syt-7 using directly comparable measurements. We report $\mathrm{Ca}^{2+}$ sensitivities, dissociation kinetics, and membrane insertion using liposomes approximating physiological lipid compositions. Equilibrium $\mathrm{Ca}^{2+}$ titrations confirm that the Syt-7 C2AB tandem has a greater $\mathrm{Ca}^{2+}$ sensitivity of membrane binding than either of its individual domains. Stopped-flow fluorescence kinetic measurements show that Syt-1 C2AB dissociates from liposome membranes much more slowly than either of its isolated $\mathrm{C} 2$ domains, suggesting that the two $\mathrm{C} 2$ domains of Syt-1 bind membranes cooperatively. In contrast, the dominant population of Syt-7 $\mathrm{C} 2 \mathrm{AB}$ has a dissociation rate comparable to its $\mathrm{C} 2 \mathrm{~A}$ domain, indicating a lack of cooperativity, while only a small subpopulation dissociates at a slower rate. Measurements using an environment-sensitive fluorescent probe indicate that the Syt-7 C2B domain inserts more deeply into membranes as part of the C2AB tandem, similarly to Syt-1. Overall, these measurements are consistent with a model in which the structural linkage of C2A and $\mathrm{C} 2 \mathrm{~B}$ impacts the membrane-binding geometry of synaptotagmin $\mathrm{C} 2 \mathrm{~B}$ domains, but imparts little or no cooperativity to Syt-7 membrane binding and dissociation events that are dominated by its $\mathrm{C} 2 \mathrm{~A}$ domain.
\end{abstract}




\section{Introduction}

Synaptotagmins are a family of proteins that trigger and regulate fusion of secretory vesicles with the plasma membrane during exocytosis (1-3). Structurally, synaptotagmins contain an N-terminal transmembrane region, a cytoplasmic juxtamembrane linker region, and tandem C-terminal $\mathrm{C} 2$ domains, termed $\mathrm{C} 2 \mathrm{~A}$ and $\mathrm{C} 2 \mathrm{~B}$. In eight of the seventeen mammalian isoforms, the $\mathrm{C} 2$ domains together function as a $\mathrm{Ca}^{2+}$ sensor to trigger SNARE-mediated membrane fusion (3-5). Although the synaptotagmins are structurally homologous, their $\mathrm{Ca}^{2+}$ and membrane binding sensitivities vary (6).

This study focuses on C2 domains from Syt-1 and Syt-7, two isoforms that serve as models for high-speed and high-sensitivity $\mathrm{Ca}^{2+}$-dependent vesicle fusion, respectively (7). Syt-1 serves as a primary $\mathrm{Ca}^{2+}$ sensor in the fast, synchronous release of neurotransmitters, while Syt-7 is involved in asynchronous neurotransmitter release, vesicle replenishment, synaptic facilitation, and endocrine and neuroendocrine secretion processes that occur at relatively low $\mathrm{Ca}^{2+}$ concentrations (8-12). Correspondingly, C2 domains of Syt-7 were found to be 400-fold more sensitive to $\mathrm{Ca}^{2+}$ than Syt-1 and have the slowest membrane dissociation kinetics among the synaptotagmins $(13,14)$. Both of the individual C2 domains from Syt-7 bind more tightly to membranes in the presence of $\mathrm{Ca}^{2+}$ than their respective counterparts in Syt-1 (15-18).

$\mathrm{Ca}^{2+}$-dependent membrane binding of synaptotagmin $\mathrm{C} 2$ domains is mediated by conserved aspartate residues in each domain's $\mathrm{Ca}^{2+}$-binding loops (CBLs), of which CBL1 and CBL3 insert into membranes upon binding $\mathrm{Ca}^{2+}(19-25)$. The structural origins of membrane binding differences between Syt-1 and Syt-7 are not yet completely clear, although some features that contribute to the strong membrane binding of Syt- 7 have been identified $(16,17,26)$. In addition to their $\mathrm{Ca}^{2+}$-dependent membrane binding, the $\mathrm{C} 2 \mathrm{~B}$ domains of both isoforms contain a polybasic lysine-rich patch centered on the $\beta-4$ strand, which has been shown to bind preferentially to polyanionic phospholipids such as phosphatidylinositol-(4,5)-bisphosphate $\left(\mathrm{PIP}_{2}\right)$ in a manner that is partially $\mathrm{Ca}^{2+}$-independent $(17,27-30)$. The stronger affinity of Syt-1 $\mathrm{C} 2 \mathrm{AB}$ for membranes containing $\mathrm{PIP}_{2}$ manifests primarily through slower dissociation kinetics $\left(k_{\text {off }}\right)$, whereas association rates $\left(k_{\text {on }}\right)$ are essentially independent of lipid composition (30).

Mutational studies of Syt-1 and Syt-7 have revealed an interesting difference between the two proteins in the relative functional importance of the two $\mathrm{C} 2$ domains. The ability of Syt-1 to trigger fusion appears to depend more on $\mathrm{Ca}^{2+}$ binding by its $\mathrm{C} 2 \mathrm{~B}$ domain, whereas Syt-7 appears to be dominated by its $\mathrm{C} 2 \mathrm{~A}$ domain. In particular, neutralization of $\mathrm{Ca}^{2+}$-binding aspartate residues in the $\mathrm{C} 2 \mathrm{~B}$ domain of Syt-1 attenuates synchronous neurotransmitter release much more severely than corresponding mutations in the $\mathrm{C} 2 \mathrm{~A}$ domain $(31,32)$. However, fusion events mediated by Syt-7 display the opposite pattern: they are more sensitive to mutations in the $\mathrm{Ca}^{2+}$-coordinating residues of the Syt-7 C2A domain $(9,11,33)$. In vitro membrane binding measurements also indicate that $\mathrm{C} 2 \mathrm{~B}$ dominates membrane binding in Syt-1 while C2A 
dominates in Syt-7 (17). In principle, differences between how these two sets of C2 domains work together could reflect functional specialization of the synaptotagmin isoforms.

In light of these findings, it has become essential to understand how the C2A and C2B domains work together to bind and insert into membranes, including comparisons between Syt-1 and Syt-7. Several studies have addressed this question for Syt-1, and have found that its C2 domains can either bind to the same target membrane or bridge between two opposing membrane surfaces $(24,34,35)$. Indeed, a combination of these modalities can exist simultaneously depending on the protein used, the lipid composition, and the protein-to-lipid ratio $(29,36)$. It has also been reported that Syt-1 C2AB membrane binding is cooperative, on the basis of observations that both $\mathrm{C} 2$ domains co-penetrate a target membrane more deeply when present as the $\mathrm{C} 2 \mathrm{AB}$ tandem than as isolated individual domains $(22,37)$. Biophysically, cooperativity implies that additional free energy stabilization is achieved by the combination of the C2A and $\mathrm{C} 2 \mathrm{~B}$ domains, beyond that which would be expected from simply linking any two membranebinding protein domains together, i.e. from avidity effects (38). This cooperative model has been supported by single-molecule force measurements on Syt-1, for which C2AB domain dissociation from a target membrane was detected as single events that required a greater pulling force than the individual domains $(39,40)$. Additionally, a study replaced the C2A-C2B linker region of Syt-1 with a rigid polyproline helix and observed length-dependent effects on both membrane binding in vitro and secretion from neurons, further suggesting that co-insertion of the two domains may be functionally important (41).

In contrast to this model of cooperative membrane binding by the $\mathrm{C} 2$ domains of Syt- 1 , we have previously reported that the $\mathrm{C} 2$ domains of Syt-7 bind a target membrane independently (42). This assessment was made on the basis of both single-molecule diffusion measurements on planar supported lipid bilayers and dissociation kinetics from liposomes. In this model of independent membrane binding, the $\mathrm{C} 2 \mathrm{AB}$ tandem domain is still predicted to have a stronger membrane affinity and $\mathrm{Ca}^{2+}$ sensitivity than the individual domains, due to avidity effects in which the binding strength of a multivalent protein-ligand interaction is enhanced due to the presence of multiple binding sites (38). However, the two binding sites do not strengthen one another's affinity; i.e., two domains bind better than one but the effects are not synergistic.

In the present study, we sought to compare more directly the extent of cooperativity in C2AB membrane binding between Syt-1 and Syt-7. First, we measured $\mathrm{Ca}^{2+}$ sensitivity for Syt7 C2A, C2B, and C2AB domains toward liposomes of physiological lipid compositions, with and without $\mathrm{PIP}_{2}$. Second, we performed direct side-by-side comparisons of liposome dissociation kinetics between Syt-1 and Syt-7 C2A, C2B, and C2AB domains, using the approach developed in our previous study (42). Finally, we applied an environment-sensitive fluorescent reporter assay with Syt-7 that was previously described and used to show copenetration of the tandem C2 domains from Syt-1 (22). Together, the results show structural similarities but kinetic differences between C2AB domains of Syt-1 and Syt-7, which can be 
bioRxiv preprint doi: https://doi.org/10.1101/393702; this version posted August 20, 2018. The copyright holder for this preprint (which was not certified by peer review) is the author/funder, who has granted bioRxiv a license to display the preprint in perpetuity. It is made available under aCC-BY-NC-ND 4.0 International license.

understood in terms of the relative energetics of membrane binding by these proteins' component C2 domains. 


\section{Materials and Methods}

\section{Materials}

1,2-Dioleoyl-sn-glycero-3-phosphocholine (DOPC), 1-palmitoyl-2-oleoyl-sn-glycero-3phosphocholine (POPC), 1,2-dioleoyl-sn-glycero-3-phospho-L-serine (sodium salt) (DOPS), 1palmitoyl-2-oleoyl-sn-glycero-3-phosphoserine (POPS), liver phosphatidylinositol (PI), 1palmitoyl-2-oleoyl-sn-glycero-3-phosphoethanolamine (POPE), brain phosphatidylinositol-4,5bisphosphate $\left(\mathrm{PIP}_{2}\right)$, cholesterol $(\mathrm{CH})$, and brain sphingomyelin $(\mathrm{SM})$ were from Avanti Polar Lipids (Alabaster, AL). 1,2-dipalmitoyl-sn-glycero-3-phosphoethanolamine-N-(5dimethylamino-1-naphthalenesulfonyl) (Dansyl-PE) was from NOF America (White Plains, NY). 3-[(3-Cholamidopropyl)dimethylammonio]-1-propanesulfonate (CHAPS) was from BioVision (Milpitas, CA). 5-(\{2-[(iodoacetyl)amino]ethyl $\}$ amino)naphthalene-1-sulfonic acid (IAEDANS) was from Molecular Probes (Eugene, OR). 2-Mercaptoethanol ( $\beta \mathrm{ME}$ ) and ethylenediamine tetraacetic acid, tetrasodium salt (EDTA) were from Fisher Scientific (Hampton, NH) ( $\geq 99 \%$ purity). All reagents were American Chemical Society (ACS) grade or higher.

\section{Protein Cloning, Expression, and Purification}

cDNA of human Syt-7 (IMAGE ID: 40121712) and Syt-1 (IMAGE ID: 6187902) were obtained from American Type Culture Collection. Sequences encoding the Syt-7 C2A domain (residues N135-S266), Syt-7 C2B domain (S261-A403), Syt-7 C2AB domain (N135-A403), Syt1 C2A domain (K141-E272), Syt-1 C2B domain (S265-K422), and Syt-1 C2AB domain (K141K422) were subcloned into a glutathione S-transferase (GST)-fusion vector developed previously $(15,43)$. All DNA sequences were verified using primer extension sequencing (Eton Bioscience, San Diego, CA). Plasmids were transformed into Escherichia coli BL-21 for protein expression.

All proteins were purified using glutathione affinity chromatography. Cells were lysed in lysis buffer (50 mM Tris, $400 \mathrm{mM} \mathrm{NaCl}, 1 \%$ triton X-100, $1 \mathrm{mM} \beta \mathrm{ME} \mathrm{pH} 7.5$ with protease inhibitors) using a Sonics VibraCell sonicator with a 6-mm probe. For single domains, lysates were treated with DNase (2 U/mL) obtained from Sigma Aldrich (St. Louis, MO) for 30 minutes. Lysates were centrifuged to pellet insoluble matter, and supernatants were incubated with glutathione sepharose 4B beads (GE Healthcare, Chicago, IL) for 3 hours at $4{ }^{\circ} \mathrm{C}$. After incubation, the beads were washed extensively with $50 \mathrm{mM}$ Tris base, $400 \mathrm{mM} \mathrm{NaCl}, 1 \mathrm{mM}$ $\beta \mathrm{ME}, \mathrm{pH} 7.5$ and subsequently with $50 \mathrm{mM}$ Tris, $1.1 \mathrm{M} \mathrm{NaCl}, 5 \mathrm{mM}$ EDTA, $1 \mathrm{mM} \beta \mathrm{ME}, \mathrm{pH}$ 7.5. Beads were then exchanged into $50 \mathrm{mM}$ Tris base, $150 \mathrm{mM} \mathrm{NaCl}, 0.05 \mathrm{mM}$ EDTA, $1 \mathrm{mM}$ $\beta \mathrm{ME} \mathrm{pH} 7.7$ for cleavage with restriction grade thrombin (Novagen, Millipore Sigma, Billerica, MA), and eluted using the thrombin cleavage buffer or Buffer A (25 mM HEPES, $15 \mathrm{mM} \mathrm{NaCl}$, $140 \mathrm{mM} \mathrm{KCl}, 0.5 \mathrm{mM} \mathrm{MgCl} 2, \mathrm{pH}$ 7.4) plus $1 \mathrm{mM} \beta \mathrm{ME}$. $\beta \mathrm{ME}$ was omitted during purification of wild-type Syt-1 C2A. For Syt-7 C2AB, 1-3 mM CHAPS was added to all wash and elution buffers.

Proteins for $\mathrm{Ca}^{2+}$ dependence and kinetic experiments were immediately purified further via gel filtration (Syt-1 C2A) or cation exchange (all other C2 fragments) chromatography using 
an Akta Purifier FPLC system (GE Healthcare). Gel filtration was performed using a Superdex G75 10/300 GL column (GE Healthcare) in Buffer A. Cation exchange was performed using a HiTrap SP HP $5 \mathrm{~mL}$ column (GE Healthcare) in Buffer A plus $1 \mathrm{mM} \beta \mathrm{ME}$ and protein was eluted with a gradient of $\mathrm{NaCl}$. Representative chromatograms are shown in Figure S1. Protein integrity was confirmed using SDS-PAGE (Figure S2), and masses were further verified using MALDI. Absorbance spectra were measured using a Nanodrop 2000 spectrometer (Thermo Fisher Scientific) to assess removal of nucleic acids. All purified proteins had $\mathrm{A}_{260} / \mathrm{A}_{280}$ ratios $\leq$ 0.54 , indicating the absence of nucleic acid contamination (44). Finally, protein concentrations were measured using UV absorbance (PerkinElmer) based on predicted extinction coefficients at $280 \mathrm{~nm}$ (http://protcalc.sourceforge.net). The purified proteins were aliquoted, flash-frozen, and stored at $-80{ }^{\circ} \mathrm{C}$. Prior to use, aliquots were thawed and centrifuged at $17000 \times \mathrm{g}$ for 2 minutes to remove any debris, and the UV absorbance spectrum was re-checked to verify protein concentration and lack of nucleic acid.

\section{Liposome Preparation}

Phospholipids in chloroform were combined at the desired molar ratio for each experiment (Table 1). After the evaporation of chloroform, the lipid films were dried under vacuum for $\geq 2$ hours and rehydrated in Buffer A containing $10 \mathrm{mM} \beta \mathrm{ME}$ to a final concentration of $3 \mathrm{mM}$ total lipid. Small unilamellar vesicles (SUVs) were prepared by sonication to clarity on ice using a Sonics VibraCell sonicator with a 3-mm tip. Liposomes were stored at $4{ }^{\circ} \mathrm{C}$ for at least 8 hours after preparation, and were used within one week. Lipid concentrations are reported as total accessible lipid, which is assumed to be one-half of the total lipid present (i.e., lipids are assumed to be evenly distributed between inner and outer leaflets).

Table 1. Lipid compositions used in this study.

Target Membrane Lipid Compositions (mol \%)

\begin{tabular}{ccccccccc}
\hline Name & PE & $\mathrm{PC}^{a}$ & $\mathrm{PS}^{a}$ & $\mathrm{PI}$ & $\mathrm{PIP}_{2}$ & $\mathrm{SM}$ & $\mathrm{CH}$ & Dansyl-PE $^{b}$ \\
\hline PM & 27.9 & 10.7 & 21.3 & $3.6^{c}$ & $2.0^{c}$ & 4.5 & 25 & 5.0 \\
& & & & & & & & \\
$\mathrm{PM}(-) \mathrm{PIP}_{2}$ & 27.9 & 10.7 & 21.3 & 5.6 & - & 4.5 & 25 & 5.0 \\
& & & & & - & - & - & 5.0 \\
$1: 1$ DOPC/DOPS & - & 47.5 & 47.5 & - & - & & &
\end{tabular}

${ }^{a}$ POPC and POPS were used for the physiological membranes, while DOPC and DOPS were used for the simplified lipid composition for consistency with prior experiments (42).

${ }^{b}$ For AEDANS fluorescence measurements, dansyl-PE was omitted and replaced with PC.

${ }^{c}$ For AEDANS fluorescence measurements, PM liposomes contained 4.6\% PI and 1.0\% $\mathrm{PIP}_{2}$. 


\section{Equilibrium Measurement of $\mathrm{Ca}^{2+}$-Dependent Protein-to-Membrane FRET}

Buffers were prepared using Chelex-treated $\mathrm{Ca}^{2+}$-free water. Liposomes were incubated with $10 \%(\mathrm{v} / \mathrm{v})$ Chelex beads (Bio-Rad) overnight at $4{ }^{\circ} \mathrm{C}$ to remove residual $\mathrm{Ca}^{2+}$. Protein stocks were dialyzed into $\mathrm{Ca}^{2+}$-free Buffer A. Quartz cuvettes were soaked in $100 \mathrm{mM}$ EDTA then rinsed extensively with $\mathrm{Ca}^{2+}$-free water prior to use. Steady-state fluorescence experiments were performed using a Photon Technology International QM-2000-6SE fluorescence spectrometer at $25{ }^{\circ} \mathrm{C}$. Excitation slit width was $2.4 \mathrm{~nm}$ for Syt-7 C2B on PM liposomes, and $1 \mathrm{~nm}$ for all other samples; emission slit width was $8 \mathrm{~nm}$. $\mathrm{CaCl}_{2}$ was titrated into an initially $\mathrm{Ca}^{2+}$-free solution containing protein $(0.3 \mu \mathrm{M})$ and liposomes $\left(75 \mu \mathrm{M}\right.$ accessible lipid). Due to the extreme $\mathrm{Ca}^{2+}$ sensitivity of Syt-7 C2 domains, a $\mathrm{Ca}^{2+}$ buffering system containing $1.5 \mathrm{mM}$ nitrilotriacetic acid (NTA) was used in order to maintain total $\left[\mathrm{Ca}^{2+}\right]$ in excess of protein, as described previously (15). Concentrations of free $\mathrm{Ca}^{2+}$ and $\mathrm{Mg}^{2+}$ (the latter held constant at $0.5 \mathrm{mM}$ ) were calculated using MaxChelator (http://maxchelator.stanford.edu). Fluorescence resonance energy transfer (FRET) was measured $\left(\lambda_{\text {excitation }}=284 \mathrm{~nm}, \lambda_{\text {emission }}=510 \mathrm{~nm}\right)$ over a 10 -s integration time for each cuvette. Each intensity value was corrected for dilution, and the intensity of a blank sample containing only buffer, lipid, and $\mathrm{Ca}^{2+}$ was subtracted. Reversibility was demonstrated by adding excess EDTA after titrations (Figure S3). In order to determine the $\mathrm{Ca}_{1 / 2}$ and Hill coefficient of each $\mathrm{C} 2$ domain, normalized data were fitted to the Hill equation,

$$
\Delta \mathrm{F}=\Delta \mathrm{F}_{\max }\left(\frac{\left[C a^{2+}\right]^{H}}{\left[C a^{2+}\right]^{H}+\left(C a_{1 / 2}\right)^{H}}+\Delta \mathrm{F}_{0}\right)
$$

where $\Delta \mathrm{F}$ is the fluorescence increase, $\mathrm{H}$ is the Hill coefficient, $\Delta \mathrm{F}_{0}$ is the fluorescence change in the absence of $\mathrm{Ca}^{2+}$, and $\Delta \mathrm{F}_{\max }$ is the calculated maximal fluorescence change. Fitting was performed using Kaleidagraph 4.5 (Synergy Software). Data in figures are shown following normalization of $\Delta \mathrm{F}_{\max }$ to unity for each titration.

\section{Stopped-Flow Spectroscopy}

Stopped-flow fluorescence kinetic measurements were performed using a BioLogic SFM3000 spectrophotometer (Knoxville, TN) using $284 \mathrm{~nm}$ excitation and a $455 \mathrm{~nm}$ long-pass emission filter. Unless otherwise noted, protein concentrations used were $1 \mu \mathrm{M}$ for Syt-7 C2 domains and Syt-1 C2AB, and $5 \mu \mathrm{M}$ for individual Syt-1 C2 domains (all concentrations listed are before mixing). Protein-to-membrane FRET (dansyl-PE emission) was monitored following rapid mixing of equal volumes of protein-bound liposomes (200 $\mu \mathrm{M}$ total accessible lipid, $200 \mu \mathrm{M} \mathrm{CaCl}_{2}$ ) and $2 \mathrm{mM}$ EDTA in Buffer A. Dead time is estimated to be $1.4 \mathrm{~ms}$. Data sets for each sample were calculated as the average of 8 or more time courses, and were fitted to a single- or double-exponential function (equation 2 or 3 , respectively):

$$
\begin{gathered}
F=\Delta F_{\max }\left(e^{-k_{\text {off }} t}\right)+C \\
F=\Delta F_{\max 1}\left(e^{-k_{\text {off } 1} t}\right)+\Delta F_{\max 2}\left(e^{-k_{\text {of } 2} t}\right)+C
\end{gathered}
$$


where the $\mathrm{k}_{\text {off }}$ are dissociation rate constants and $\mathrm{C}$ is an offset. $\mathrm{C}$ was subtracted and $\Delta \mathrm{F}_{\max }$ (or $\left.\Delta \mathrm{F}_{\max 1}+\Delta \mathrm{F}_{\max 2}\right)$ normalized to unity in the figures shown. Rate constants listed are averages \pm standard deviation of $\geq 3$ independent replicate measurements.

\section{Dynamic Light Scattering}

The $Z$-average diameter of liposome suspensions (1:1 DOPC/DOPS, $200 \mu \mathrm{M}$ accessible lipids, $100 \mu \mathrm{M} \mathrm{Ca}^{2+}$ ) was determined using a Zetasizer Nano S90 (Malvern Instruments) before and after addition of protein. The samples were removed from the DLS instrument and used for stopped-flow kinetic measurements as described above.

\section{Purification of AEDANS-labeled Proteins}

In order to facilitate labeling, native cysteine residues were removed from the proteins and unique cysteines were inserted using site-directed mutagenesis (Quik-Change II XL, Agilent). A Cys to Ala substitution was performed at C275 in Syt-7 C2AB and C2B. (Note: the C275A mutant of Syt-7 C2B was also used for all Syt-7 C2B kinetic experiments, as this mutation greatly simplified purification of the protein which otherwise had a propensity to form disulfide-linked dimers.) C260 was mutated to Ser in Syt-7 C2A and C2AB; we have previously reported that this mutation has only minor effects on the C2A domain (16). For AEDANS attachment, the following residues in the calcium binding loops 1 and 3 of the Syt-7 C2A, C2B, and C2AB domain were mutated to cysteine: T170 (C2A loop 1), N232 (C2A loop 3), T301 (C2B loop 1), and N364 (C2B loop 3). Mutations were confirmed using primer-extension sequencing (Eton Biosciences). Proteins were expressed and purified using glutathione affinity chromatography as described above, except that $0.5 \mathrm{mM}$ TCEP was used in place of $1 \mathrm{mM} \beta \mathrm{ME}$ for all domains, and $2.5 \mathrm{mM} \mathrm{CaCl}_{2}$ was included in the thrombin cleavage buffer for $\mathrm{C} 2 \mathrm{~B}$. After thrombin cleavage and elution, protein concentrations were estimated from absorbance at 280 $\mathrm{nm}$, and the proteins were incubated with IAEDANS (4:1 molar ratio of IAEDANS to protein). For single domains, proteins were labeled in $140 \mathrm{mM} \mathrm{KCl}, 0.5 \mathrm{mM} \mathrm{MgCl}_{2}, 25 \mathrm{mM} \mathrm{HEPES}$, $50 \mathrm{mM}$ glutamic acid, $50 \mathrm{mM}$ arginine $\mathrm{pH} 7.1$ overnight at $4{ }^{\circ} \mathrm{C}(45)$. For $\mathrm{C} 2 \mathrm{AB}$ tandems, proteins were labeled in thrombin cleavage buffer for 1 hour at room temperature. The reaction was quenched by adding $1 \mathrm{mM} \beta \mathrm{ME}$. To remove free dye and anionic contaminants, the proteins were further purified using cation exchange chromatography as described above, including 20 $\mathrm{mM} \mathrm{CaCl}_{2}$ in the chromatography buffers. Following chromatography, proteins were exchanged into Buffer A plus $1 \mathrm{mM} \beta \mathrm{ME}$. Protein mass and labeling was verified using SDS-PAGE gel electrophoresis with visualization under ultraviolet light, and concentration was quantified based on AEDANS absorbance.

\section{AEDANS fluorescence assays}

AEDANS fluorescence was measured using a Photon Technology International QM2000-6SE fluorescence spectrometer at $25^{\circ} \mathrm{C}$. Fluorescence emission scans were measured scanning from 450 to $600 \mathrm{~nm}$, with $\lambda_{\text {excitation }}=337 \mathrm{~nm}$. Excitation slit widths were $1 \mathrm{~nm}$ except 
bioRxiv preprint doi: https://doi.org/10.1101/393702; this version posted August 20,2018 . The copyright holder for this preprint (which was not certified by peer review) is the author/funder, who has granted bioRxiv a license to display the preprint in perpetuity. It is made available under aCC-BY-NC-ND 4.0 International license.

the following samples: $\mathrm{C} 2 \mathrm{~A}^{3} \mathrm{~B}, 1.6 \mathrm{~nm} ; \mathrm{C} 2 \mathrm{AB}^{1}, 1.6 \mathrm{~nm} ; \mathrm{C}^{\mathrm{A}} \mathrm{AB}^{3}, 2.4 \mathrm{~nm}$. Emission slit widths were $8 \mathrm{~nm}$ for all measurements. All measurements were carried out with $0.5-1 \mu \mathrm{M}$ protein in Buffer A with $0.2-1.0 \mathrm{mM} \mathrm{Ca}^{2+}$ before and after addition of liposomes (33 $\mu \mathrm{M}$ total lipid). 


\section{Results}

Strategy and protein purification

This study was designed to compare C2A-C2B interdomain cooperativity in Syt-1 and Syt-7; that is, whether a greater energetic stabilization is afforded by membrane binding for each $\mathrm{C} 2 \mathrm{AB}$ tandem compared to the sum of the individual $\mathrm{C} 2 \mathrm{~A}$ and $\mathrm{C} 2 \mathrm{~B}$ domains. Thus, we expressed and purified individual domains and C2AB tandems of both Syt-1 and Syt-7 (Figures S1-S2). Initial purification was accomplished using affinity chromatography with cleavable GST tags. Because the Syt-1 C2B domain and both Syt-7 C2 domains are cationic and tend to copurify with anionic contaminants, these individual domains and both $\mathrm{C} 2 \mathrm{AB}$ tandem domains were additionally purified using cation exchange chromatography (Figure S1) $(15,17,46)$. Syt-1 C2A was purified using glutathione affinity chromatography followed by gel filtration (Figure S1). Purity of all six protein domains was excellent as assessed using SDS-PAGE, UV absorbance, and MALDI mass spectrometry (see Methods).

$\mathrm{Ca}^{2+}$ Sensitivity of Syt7 C2 Domains

The $\mathrm{Ca}^{2+}$ sensitivities and cooperativities of membrane binding were compared among individual and tandem C2 domains of Syt-7 (Figure 1, Table 2). For many $\mathrm{C} 2$ domains, including those from synaptotagmins, titration with $\mathrm{Ca}^{2+}$ in the presence of liposome membranes produces sigmoidal binding curves with a characteristic $\mathrm{Ca}_{1 / 2}\left(\left[\mathrm{Ca}^{2+}\right]\right.$ at which the protein is half-maximally membranebound) and a Hill coefficient $>1$ arising from cooperative binding of multiple $\mathrm{Ca}^{2+}$ ions and membrane to each domain (47). In order to compare these parameters for Syt-7 C2A, C2B, and C2AB domains, $\mathrm{Ca}^{2+}$ was titrated into solutions containing protein and liposomes with lipid compositions approximating the interior leaflet of the plasma membrane, with or without $\mathrm{PIP}_{2}$ (Table 1), and protein-tomembrane FRET was monitored (48). Due to the strong $\mathrm{Ca}^{2+}$ sensitivity of Syt-7, solutions were treated to remove as much free $\mathrm{Ca}^{2+}$ as possible and a $\mathrm{Ca}^{2+}$ buffering

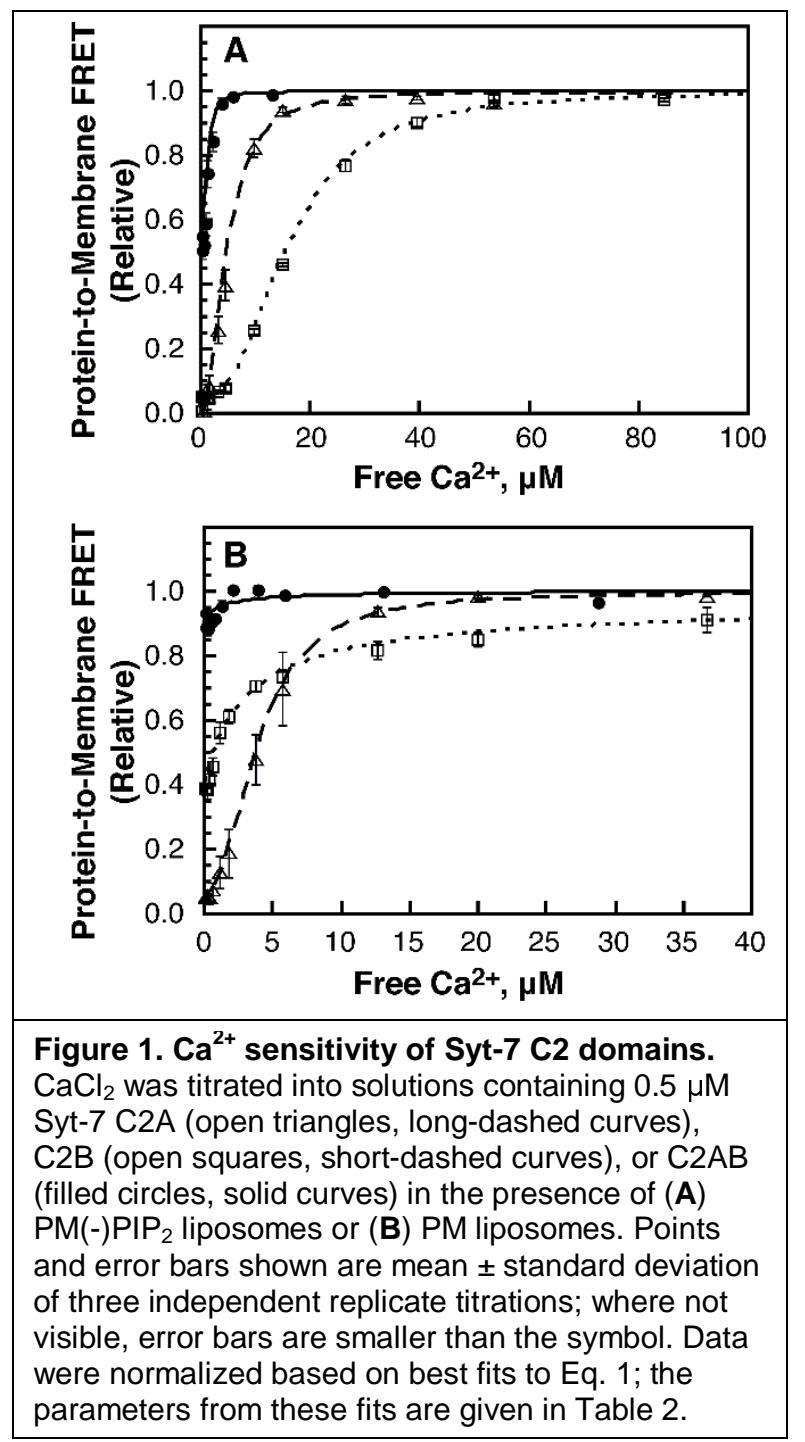


system was used to enable reliable measurement of binding even at free $\mathrm{Ca}^{2+}$ concentrations less than the protein concentration (15). Consistent with a previous report, the Syt-7 C2A domain bound liposomes containing a physiological membrane composition without $\mathrm{PIP}_{2}\left[\mathrm{PM}(-) \mathrm{PIP}_{2}\right.$, Table 1] with a $\mathrm{Ca}_{1 / 2}$ around $5 \mu \mathrm{M}$ and a Hill coefficient of 2.2 (Table 2) (15). Inclusion of PIP 2 in the membrane had little impact on the $\mathrm{Ca}_{1 / 2}$ and Hill coefficient for this domain (Table 2).

Table 2. Equilibrium $\mathrm{Ca}^{2+}$ titration parameters of Syt-7 C2 domains

\begin{tabular}{cccc}
\hline $\begin{array}{c}\text { Liposome composition } \\
\text { (See Table 1) }\end{array}$ & Domain & $\mathrm{Ca}_{1 / 2}(\mu \mathrm{M})^{a}$ & Hill Coeff $^{a}$ \\
\hline PM(-)PIP 2 & Syt-7 C2A & $4.8 \pm 0.4$ & $2.2 \pm 0.1$ \\
PM(-)PIP 2 & Syt-7 C2B & $16.0 \pm 0.5$ & $2.5 \pm 0.1$ \\
PM(-)PIP 2 & Syt-7 C2B C275A & $15.1 \pm 0.6$ & $2.7 \pm 0.2$ \\
PM(-)PIP 2 & Syt-7 C2AB & $<1^{b}$ & N.D. ${ }^{b}$ \\
PM & Syt-7 C2A & $4.0 \pm 1.0$ & $2.2 \pm 0.2$ \\
PM & Syt-7 C2B & $<2^{b}$ & N.D. ${ }^{b}$ \\
PM & Syt-7 C2AB & $<1^{b}$ & N.D. ${ }^{b}$ \\
\hline
\end{tabular}

${ }^{\bar{a}} \mathrm{Ca}_{1 / 2}$ and Hill coefficients were obtained from fitting to Eq. 1 .

${ }^{b} \mathrm{Ca}_{1 / 2}$ and Hill coefficient could not be determined accurately due to significant liposome binding prior to $\mathrm{Ca}^{2+}$ addition (Figure 1).

In contrast, the Syt-7 C2B domain showed a pronounced $\mathrm{PIP}_{2}$ dependence, consistent with a previous report (17). In the absence of $\mathrm{PIP}_{2}$, Syt-7 C2B bound liposome membranes with somewhat weaker $\mathrm{Ca}^{2+}$ sensitivity than the $\mathrm{C} 2 \mathrm{~A}$ domain (Figure $1 \mathrm{~A}$ ), but the trend was reversed upon inclusion of $1 \% \mathrm{PIP}_{2}$ in the membrane, as the protein was partially membrane-bound even prior to $\mathrm{Ca}^{2+}$ addition (Figure 1B). This result suggests that Syt-7 C2B has a binding mode to $\mathrm{PIP}_{2}$ that is either $\mathrm{Ca}^{2+}$-insensitive or has a $\mathrm{Ca}_{1 / 2}$ near the limit of measurement. We estimate the level of $\mathrm{Ca}^{2+}$ contamination in these measurements to be $<1 \mu \mathrm{M}$; thus, the Syt-7 C2B domain can bind membranes containing $\mathrm{PIP}_{2}$ even at very low $\mathrm{Ca}^{2+}$ concentrations. This binding was reversed upon addition of the $\mathrm{Ca}^{2+}$ chelator EDTA (Figure S3). The $\mathrm{Ca}^{2+}$ dependence and Hill coefficient of the Syt7 C2B domain were not significantly affected by mutation of Cys 275 to alanine (Table 2), a mutation which was required for the AEDANS measurements described below. Thus, all further experiments with Syt-7 C2B used the C275A variant. 
The Syt-7 C2AB tandem had a lower $\mathrm{Ca}_{1 / 2}$ toward PM(-)PIP 2 liposomes than either individual domain, and was approximately $50 \%$ bound to these liposomes even prior to $\mathrm{Ca}^{2+}$ addition (Figure $1 \mathrm{~A}$ ). Inclusion of $1 \% \mathrm{PIP}_{2}$ further enhanced membrane binding, as the $\mathrm{C} 2 \mathrm{AB}$ tandem was $>90 \%$ bound to $\mathrm{PM}$ liposomes prior to $\mathrm{Ca}^{2+}$ addition (Figure $1 \mathrm{~B}$ ). Binding of $\mathrm{C} 2 \mathrm{AB}$ to $\mathrm{PM}(-) \mathrm{PIP}_{2}$, but not PM, liposomes was reversed upon EDTA addition (Figure S3). Thus, the combination of the two domains increases the $\mathrm{Ca}^{2+}$ sensitivity of membrane binding, and may enhance a $\mathrm{Ca}^{2+}$-insensitive binding mode. However, it is not clear from these data whether such an enhancement arises from cooperativity or avidity effects.

\section{Assessing Cooperativity in Syt-1 and Syt-7 C2AB Domains from Dissociation Kinetics}

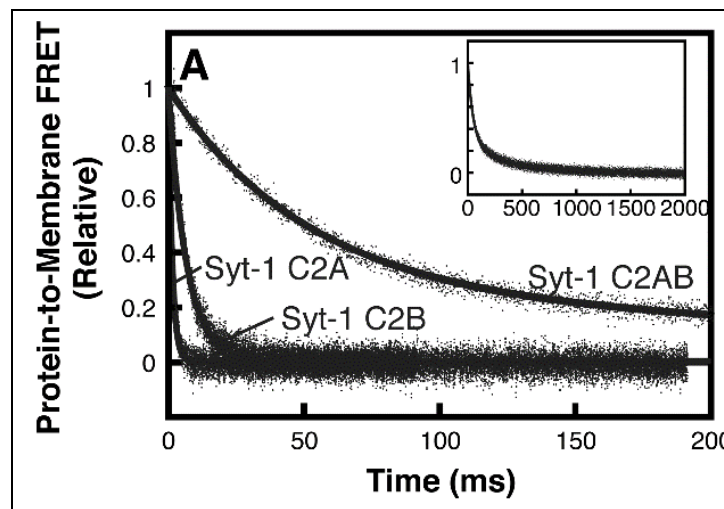

In order to probe whether the energetics

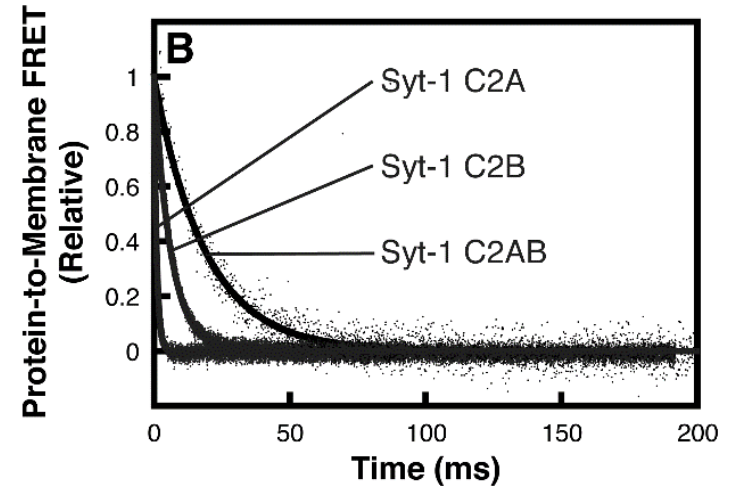

Figure 2. Dissociation kinetics of Syt-1 C2 domains on (A) 1:1 DOPC/DOPS liposomes and (B) $\mathrm{PM}(-) \mathrm{PIP}$ liposomes. Dansyl-PE fluorescence was monitored as solutions containing $5 \mu \mathrm{M}$ (single domains) or $1 \mu \mathrm{M}$ (tandem domain) protein, $200 \mu \mathrm{M}$ $\mathrm{CaCl}_{2}$, and synthetic vesicles $(200 \mu \mathrm{M}$ accessible lipid) were rapidly mixed with an equal volume of $2 \mathrm{mM}$ EDTA (all concentration listed are before mixing). Kinetic data were fit to Eq. 2 or Eq. 3, with rate constants shown in Table 3. Inset shows the full timescale of measurement of Syt-1 C2AB. Data shown are representative of $\geq 3$ independent measurements. of Syt-1 and Syt-7 C2AB membrane binding are cooperative, we measured the kinetics of proteinmembrane dissociation upon addition of the $\mathrm{Ca}^{2+}$ chelator EDTA. In this experiment, protein-tomembrane FRET decreases following the addition of EDTA to protein-liposome complexes. The EDTA coordinates $\mathrm{Ca}^{2+}$ ions as each $\mathrm{C} 2$ domain leaves the membrane surface, rendering each domain's dissociation irreversible. Thus, if the two C2 domains bind and release from membranes independently, then the dissociation kinetic profile of the $\mathrm{C} 2 \mathrm{AB}$ tandem should be closely similar to that of the rate-limiting domain. We have previously used this method to demonstrate that $\mathrm{C} 2 \mathrm{AB}$ domains of Syt-7 dissociate independently from liposomes composed of 3:1 DOPC/DOPS (42). On the other hand, if the two $\mathrm{C} 2$ domains of a $\mathrm{C} 2 \mathrm{AB}$ tandem bind membranes cooperatively, then $\mathrm{C} 2 \mathrm{AB}$ dissociation is expected to be significantly slower than both of the individual domains.

Using this approach, the tandem $\mathrm{C} 2$ domains of Syt-1 are clearly observed to bind membranes cooperatively. Although the Syt-1 C2A domain dissociated from 3:1 DOPC/DOPS too quickly to measure, we quantified dissociation kinetics of Syt-1 C2A, C2B, and

$\mathrm{C} 2 \mathrm{AB}$ using 1:1 DOPC/DOPS (Figure 2A). The individual Syt-1 C2 domains' dissociation time 
courses fit well to single exponential profiles, with the $\mathrm{C} 2 \mathrm{~A}$ rate constant similar to previous reports $(15,49)$. Dissociation of the $\mathrm{C} 2 \mathrm{~B}$ domain was slower than the $\mathrm{C} 2 \mathrm{~A}$ domain, consistent with its stronger membrane binding $(17,30,40)$.

Syt-1 C2AB dissociation was best fit by a double exponential, of which the faster rate constant was $\sim 7$-fold slower than the isolated C2B domain and $>50$-fold slower than the isolated C2A domain (Table 3). Similarly, Syt-1 C2AB dissociation from PM(-)PIP 2 liposomes was at least 3-fold slower than either the $\mathrm{C} 2 \mathrm{~A}$ or $\mathrm{C} 2 \mathrm{~B}$ domain alone (Figure $2 \mathrm{~B}$, Table 3 ). Thus, the energy barrier for membrane release upon EDTA addition is significantly greater for the Syt-1 $\mathrm{C} 2 \mathrm{AB}$ tandem than for both of its individual domains, consistent with a model of cooperative membrane insertion.

Table 3. Dissociation kinetics of Syt-1 and Syt-7 C2 domains. Double exponential rate constants are reported with their respective percent amplitudes from the best-fit curve.

\begin{tabular}{ccc}
\hline Domain & $\mathrm{k}_{\text {off }}, 1: 1 \mathrm{DOPC} / \mathrm{DOPS}\left(\mathrm{s}^{-1}\right)$ & $\mathrm{k}_{\text {off }}, \mathrm{PM}(-) \mathrm{PIP}_{2}\left(\mathrm{~s}^{-1}\right)$ \\
\hline Syt-1 C2A & $140 \pm 10$ & $1020 \pm 90$ \\
Syt-1 C2B & $21 \pm 2(72 \% \mathrm{amp})$ & \\
Syt-1 C2AB & $2.6 \pm 0.1(28 \% \mathrm{amp})$ & $78 \pm 5$ \\
& $6.39 \pm 0.04$ & $7.4 \pm 0.3$ \\
Syt-7 C2A & $80 \pm 9(88 \% \mathrm{amp})$ & $100 \pm 20$ \\
Syt-7 C2B & $13 \pm 2(12 \% \mathrm{amp})$ & $5.9 \pm 0.6(77 \% \mathrm{amp})$ \\
& $4.6 \pm 0.3(74 \% \mathrm{amp})$ & $0.64 \pm 0.09(23 \% \mathrm{amp})$ \\
\hline Syt-7 C2AB & $0.16 \pm 0.04(26 \% \mathrm{amp})$ & \\
\hline
\end{tabular}


Dissociation kinetics of Syt-7 C2 domains are largely consistent with independent membrane binding, in contrast to Syt-1 (Figure 3). Dissociation of each individual Syt-7 domain was slower than that of the corresponding Syt-1 domain, consistent with previous reports (Table 3$)(14,15)$. The difference is particularly pronounced between the C2A domains, for which Syt-7 C2A dissociated $>100$-fold slower from both membrane compositions tested. Notably, for Syt-7 the C2A domain dissociated slower than the $\mathrm{C} 2 \mathrm{~B}$ domain, in contrast to Syt-1 for which the isolated $\mathrm{C} 2 \mathrm{~B}$ domain dissociates slower. This result is consistent with prior reports that the $\mathrm{C} 2 \mathrm{~A}$ domain dominates membrane binding and fusion properties for Syt-7 $(9,11,17,33)$.

Dissociation of Syt-7 C2AB from both 1:1 DOPC/DOPS and PM(-)PIP 2 was biphasic, with a major (faster) rate constant that differed by no more than $30 \%$ from the isolated C2A domain on each liposome composition tested (Figure 3, Table 3). The double exponential character suggests the presence of multiple populations, and one possibility is that a subpopulation (20-30\%) of Syt-7 C2AB is bound to membranes in a cooperative fashion analogous to Syt-1 (see
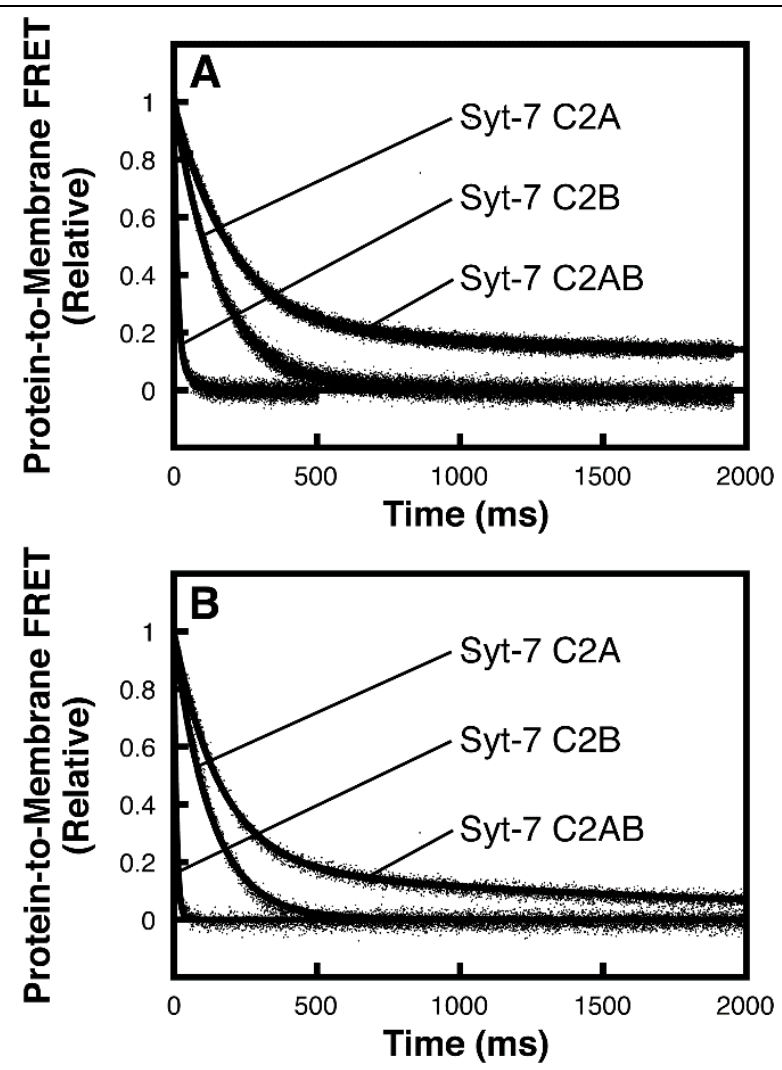

Figure 3. Dissociation kinetics of Syt-7 C2 domains on (A) 1:1 DOPC/DOPS liposomes and (B) PM(-)PIP 2 liposomes. Dansyl-PE fluorescence was monitored as solutions containing $1 \mu \mathrm{M}$ protein (in panel A) or $0.25 \mu \mathrm{M}$ protein (in panel B), $200 \mu \mathrm{M} \mathrm{CaCl}_{2}$, and liposomes $(200 \mu \mathrm{M}$ accessible lipid) were rapidly mixed with an equal volume of 2 mM EDTA (all concentrations listed are before mixing). Kinetic data were best fit to Eq. 2 or Eq. 3, with rate constants listed in Table 3. Data shown are representative of $\geq 3$ independent measurements.

Discussion). However, the larger population of Syt-7 C2AB has dissociation kinetics that are more consistent with its two $\mathrm{C} 2$ domains binding membranes independently.

\section{Liposome Clustering by Syt-7 C2B}

Some Syt C2 domains, including C2AB tandems, are known to promote clustering of liposomes in a $\mathrm{Ca}^{2+}$-dependent manner $(17,34,35,50,51)$. This effect could conceivably result in slower dissociation rates, e.g. if a subpopulation of protein is initially inaccessible to the added EDTA. In order to probe whether liposome clustering occurs under the conditions used in the measurements above, we performed dynamic light scattering measurements of 1:1 DOPC/DOPS liposomes in the presence of different concentrations of Syt-7 C2B. Addition of $0.5 \mu \mathrm{M}$ protein to liposomes resulted in a significant increase in particle size, from an average diameter of $\sim 100$ $\mathrm{nm}$ to $\sim 500 \mathrm{~nm}$ (Figure S4A). Further addition of protein to $2 \mu \mathrm{M}$ increased the size distribution 
further, to $\sim 800 \mathrm{~nm}$ (Figure S4B). These samples became visibly somewhat cloudy, but not flocculated, upon addition of $2 \mu \mathrm{M}$ protein. Thus, Syt-7 C2B induces liposome clustering, but not large-scale aggregation, under conditions comparable to those used in the kinetic measurements reported above.

This degree of clustering appears to have no effect on the major dissociation rate constants. Kinetic profiles were measured using $0.5,1$, and $2 \mu \mathrm{M}$ Syt7 C2B on the same concentration of liposomes (Figure S5). At the highest protein concentration, the dissociation profile was clearly double exponential, suggesting the presence of multiple populations. Kinetic profiles at the lower protein concentrations could also be fit to a double exponential, although the slower component was greatly decreased in intensity (Table S1). The slower phase was only a minor contributor $(<20 \%)$ to the overall kinetic profile at protein concentrations $\leq 1 \mu \mathrm{M}$. Importantly, the rate constants of the fast and slow components showed no trend among measurements using various concentrations of protein (Table S1). Thus, we conclude that liposome clustering and aggregation result in a subpopulation of protein with a significantly slower dissociation; however, at the protein concentrations used in the experiments above, the major, faster dissociation rate constant remains readily measurable. It is possible that liposome clustering may give rise to some of the minor, slower component(s) that we observe with Syt-1 and Syt-7 C2AB dissociation. However, these results support a high level of confidence that the major rate constants of the kinetic profiles correspond to straightforward protein-membrane dissociation that is not influenced by liposome aggregation effects.

\section{Membrane Insertion of Syt-7 C2 Domains}

In order to test whether the tandem structure of Syt-7 C2AB affects its C2 domains' membrane insertion, we used the environment-sensitive fluorescent probe AEDANS. This approach has been used previously to demonstrate membrane insertion of Syt-1 C2 domains (22, 23). AEDANS was attached to a unique engineered Cys residue on the tips of CBL1 and CBL3 on each Syt-7 C2 domain both individually and in the C2AB tandem (Figure S6). These are the regions that penetrate membranes in many C2 domains including those from synaptotagmins (16, 21, 52-55). Upon addition of physiological liposomes (PM(-)PIP2, Table 1) to protein in the presence of excess $\mathrm{Ca}^{2+}$, the AEDANS fluorescence emission increased and blue-shifted for both loops of C2A (Figure 4A-B) and loop 3 of C2B (Figure 5A-B). The increase in fluorescence emission was amplified for all four loops when measured in the $\mathrm{C} 2 \mathrm{AB}$ tandem (Figures $4 \mathrm{C}-\mathrm{D}$ and 5C-D). The difference between individual and tandem domains was especially striking for $\mathrm{C} 2 \mathrm{~B}$ loop 1, whose fluorescence increased dramatically upon liposome addition to the $\mathrm{C} 2 \mathrm{AB}$ tandem but not the individual C2B domain (Figure 5A,C). 

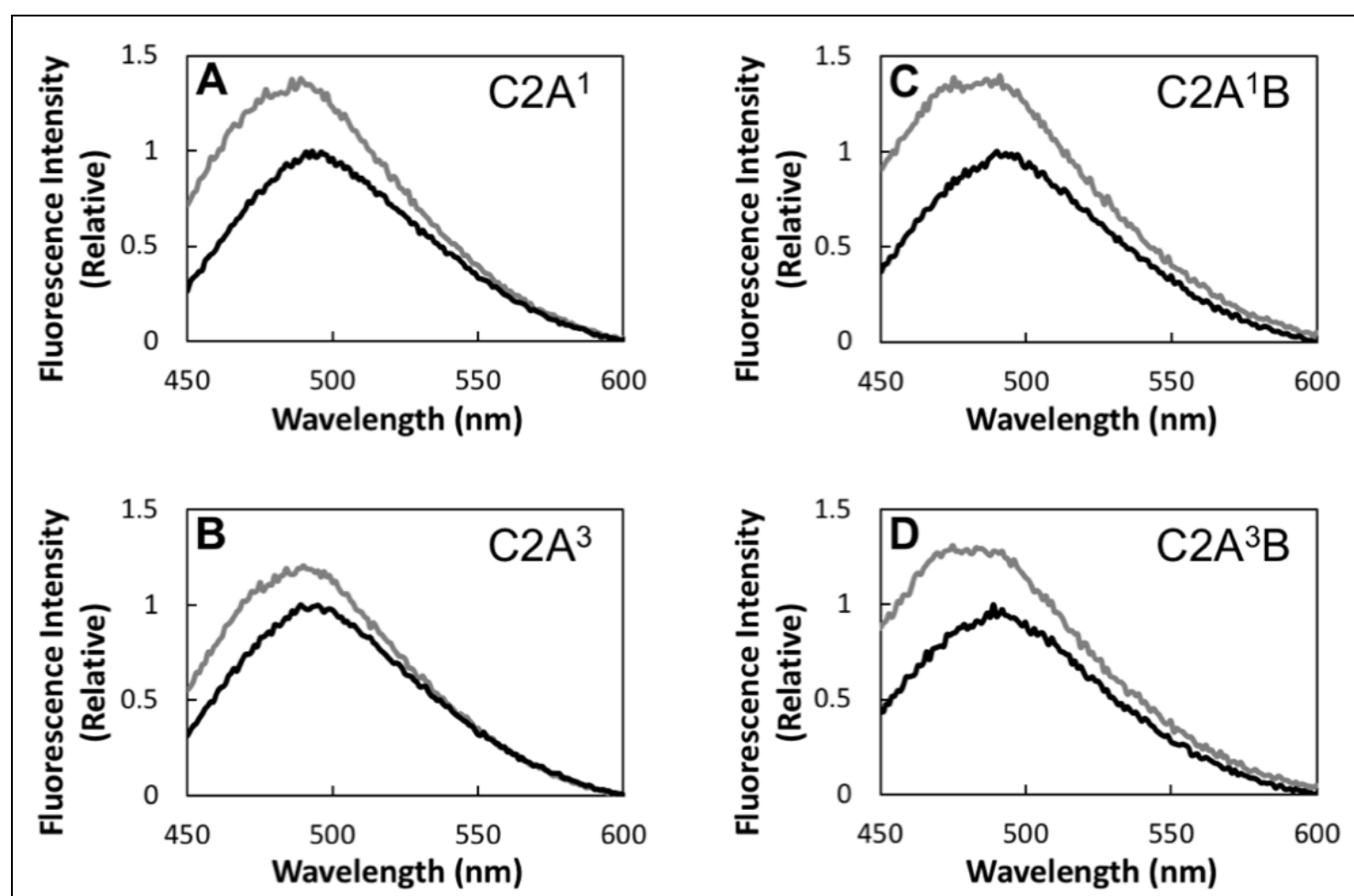

Figure 4. Membrane insertion of Syt-7 C2A domain loops in the absence of $\mathbf{P I P}_{\mathbf{2}}$. Fluorescence emission spectra are shown of Syt-7 protein domains labeled with AEDANS at (A) C2A $A^{1},(\mathbf{B}) C^{2} A^{3},(\mathbf{C})$ $\mathrm{C} 2 \mathrm{~A}^{1} \mathrm{~B}$, or (D) $\mathrm{C} 2 \mathrm{~A}^{3} \mathrm{~B}$ (see Figure $\mathrm{S} 6$ for schematic and Methods for labeled residues) in solution alone (black) and after addition of $\mathrm{PM}(-) \mathrm{PIP}_{2}$ liposomes (gray). All spectra are normalized to the maximum intensity in the absence of lipid.

Inclusion of $2 \% \mathrm{PIP}_{2}$ in the liposome composition resulted in a similar pattern, except that the amount of fluorescence increase for the individual domains was somewhat greater than in the absence of $\mathrm{PIP}_{2}$ (Figures S7-S8). Overall, the C2 domains of Syt-7 penetrate into membranes when present as single or tandem domains. However, C2B in particular penetrates significantly more deeply when it is part of the $\mathrm{C} 2 \mathrm{AB}$ tandem structure. This result is qualitatively similar to what was previously reported for Syt-1 (22). 
bioRxiv preprint doi: https://doi.org/10.1101/393702; this version posted August 20,2018 . The copyright holder for this preprint (which was not certified by peer review) is the author/funder, who has granted bioRxiv a license to display the preprint in perpetuity. It is made available under aCC-BY-NC-ND 4.0 International license.
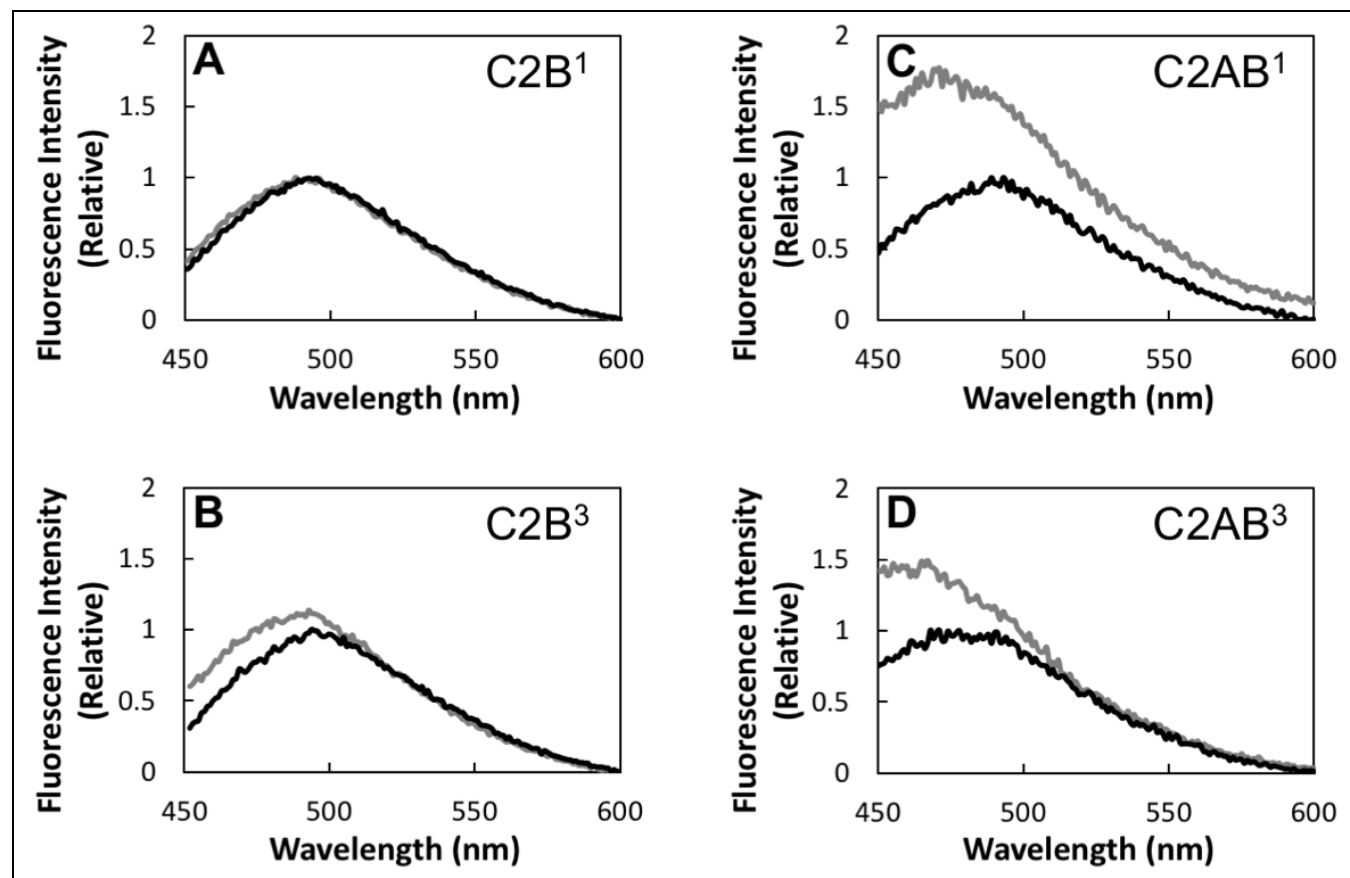

Figure 5. Membrane insertion of Syt-7 C2B domain loops in the absence of PIP $_{2}$.

Fluorescence emission spectra are shown of Syt-7 protein domains labeled with AEDANS at (A) $\mathrm{C}_{2} \mathrm{~B}^{1}$, (B) $\mathrm{C}_{2} \mathrm{~B}^{3}$, (C) $\mathrm{C} 2 \mathrm{AB}^{1}$, or (D) $\mathrm{C} 2 \mathrm{AB}^{3}$ (see Figure $\mathrm{S} 6$ for schematic and Methods for labeled residues) in solution alone (black) and after addition of PM(-)PIP 2 liposomes (gray).

All spectra are normalized to the maximum intensity in the absence of lipid. 


\section{Discussion}

In this study, we have employed FRET-based equilibrium $\mathrm{Ca}^{2+}$ titrations, stopped-flow kinetic measurements, and fluorescence-based membrane insertion assays to explore how the two C2 domains of Syt-7 work together in comparison to those of Syt-1. Four main conclusions can be drawn from the results: (i) the tandem C2 domains of Syt-1 bind membranes cooperatively, consistent with previous reports $(22,37)$; (ii) the major population of Syt-7 C2AB has dissociation kinetics that are consistent with independent, not cooperative, membrane binding (42); (iii) the Syt-7 C2AB domain is highly sensitive to $\mathrm{Ca}^{2+}$, even more so than its individual $\mathrm{C} 2$ domains, and (iv) the $\mathrm{Ca}^{2+}$-binding loops of Syt-7 C2B insert more deeply into membranes in the context of the C2AB tandem, similarly to Syt-1 (22); Although the last finding might appear to contradict a model of independent Syt-7 C2AB membrane binding, it can be understood in terms of relative contributions to binding energetics from the $\mathrm{C} 2 \mathrm{~A}$ and $\mathrm{C} 2 \mathrm{~B}$ domains, as discussed below.

\section{Cooperativity in Syt-1, Avidity in Syt-7}

We previously reported that Syt-7 C2A and C2B domains bind independently to anionic lipid membranes, based on single-molecule lateral diffusion measurements and stopped-flow spectroscopy using 3:1 DOPC/DOPS membranes (42). For the present study, it was not possible to use the lateral diffusion approach with Syt-1 due to the fast dissociation of its C2A domain. Therefore, we measured stopped-flow kinetics of dissociation from 1:1 DOPC/DOPS and $\mathrm{PM}(-) \mathrm{PIP}_{2}$ liposomes, two compositions for which dissociation rate constants were within the measurable range of the stopped-flow spectrometer for all of the protein domains investigated. These results show a clear distinction between the two proteins: for Syt-1, the C2AB tandem dissociates much slower than either of its constituent domains (Figure 2), whereas the largest population of Syt-7 C2AB dissociates at a rate comparable to its isolated C2A domain (Figure 3). All of the domains dissociated more slowly from 1:1 DOPC/DOPS than from PM(-)PIP 2 , likely due to the difference in anionic lipid content. Importantly, the trends among the various domains are generally the same for the two lipid compositions, except that a minor, slow phase was detected for Syt-1 C2AB and Syt-7 C2B on 1:1 DOPC/DOPS, possibly due to the higher anionic lipid content enabling additional liposome clustering via binding to secondary sites on the $\mathrm{C} 2 \mathrm{~B}$ domains. Thus, the present results support a model of independent membrane binding for the $\mathrm{C} 2$ domains of Syt-7, but cooperative binding for the C2 domains of Syt-1.

Dissociation of Syt-7 C2AB was biphasic on both lipid compositions tested, even at the low $0.25 \mu \mathrm{M}$ protein concentration used with $\mathrm{PM}(-) \mathrm{PIP}_{2}$. The minor, slower phase could arise from a subpopulation of protein that exhibits cooperative binding, a contribution from liposome aggregation, or a combination of these phenomena. Because the origin of heterogeneity in Syt-7 $\mathrm{C} 2 \mathrm{AB}$ is not yet clear, we focus our analysis on the dominant population which has characteristics of independent membrane binding.

The AEDANS-based membrane insertion results with Syt-7 may shed light on the structural mechanism of cooperativity in Syt-1. Similarly to Syt-1, we show that the $\mathrm{Ca}^{2+}$ binding loops of Syt-7, especially CBL1 of the C2B domain, penetrate into membranes much 
more deeply as part of the $\mathrm{C} 2 \mathrm{AB}$ tandem than in the isolated domains $(14,22)$. All four loops show robust insertion both with and without $\mathrm{PIP}_{2}$ in the context of the $\mathrm{C} 2 \mathrm{AB}$ tandem (Figures 5C-D, 6C-D, S7C-D, and S8C-D). In particular, the CBL3 of C2B inserts much deeper in the $\mathrm{C} 2 \mathrm{AB}$ tandem than in the isolated $\mathrm{C} 2 \mathrm{~B}$ domain (Figure 5B,D and Figure S8B,D). For Syt-1, the $\mathrm{C} 2 \mathrm{~B}$ domain binds membranes much more tightly than $\mathrm{C} 2 \mathrm{~A}$, even in the absence of $\mathrm{PIP}_{2}$ (Figure 2). In contrast, Syt-7 C2A binds membranes more tightly than Syt-7 C2B, at least in the absence of $\mathrm{PIP}_{2}$ (Figure 1A; Figure 3) (17). Thus, both our present results and previously reported data are consistent with a model in which the $\mathrm{C} 2 \mathrm{~B}$ domain of both isoforms is more strongly impacted by the $\mathrm{C} 2 \mathrm{AB}$ linkage (Figure 6) (22). We suggest that the deeper insertion of the $\mathrm{C} 2 \mathrm{~B}$ domain significantly slows the membrane dissociation kinetics of Syt-1 C2AB because that protein's membrane binding strength is dominated by its $\mathrm{C} 2 \mathrm{~B}$ domain. For Syt-7, membrane binding is dominated by the $\mathrm{C} 2 \mathrm{~A}$ domain, which does not penetrate much deeper in the $\mathrm{C} 2 \mathrm{AB}$ tandem. This model may explain how the energetic effects of C2A-C2B linkage differ between Syt-1 and Syt-7, even though its structural effects on membrane binding are similar for the two proteins.

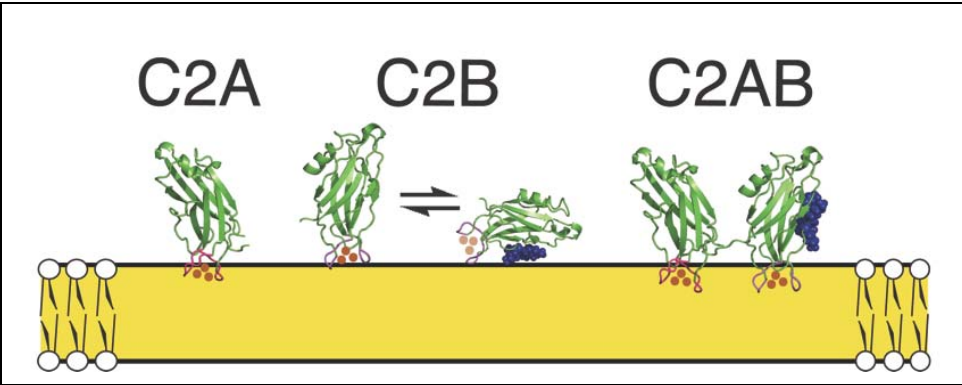

Figure 6. Structural model of linkage effects on insertion and dissociation kinetics. Syt-7 domains are drawn from published structures of C2A (PDB ID 2D8K) and C2B (56), although the model is consistent with previously reported structural data for Syt-1 (22, 30, 37). (Left) The isolated C2A domain penetrates membranes primarily via its CBLs $(16,54)$. (Center) The isolated $\mathrm{C} 2 \mathrm{~B}$ domain binds membranes relatively superficially through its CBLs and/or via interaction of its polybasic $\beta-4$ region (blue spheres) with lipid headgroups. (Right) In the C2AB tandem, both domains but especially $\mathrm{C} 2 \mathrm{~B}$ penetrate membranes more deeply. For Syt-1, because the C2B domain binds membranes relatively strongly (i.e., dissociates more slowly) in comparison to the C2A domain, its deeper insertion in the $\mathrm{C} 2 \mathrm{AB}$ tandem leads to apparent interdomain cooperativity. For Syt-7, the isolated C2A domain binds membranes more tightly than the $\mathrm{C} 2 \mathrm{~B}$ domain, at least in the absence of $\mathrm{PIP}_{2}$. Because C2A insertion is only modestly affected by $C 2 A B$ linkage, the deeper insertion of the $C 2 A B$ tandem does not contribute significantly to binding energetics and the Syt-7 C2 domains do not display cooperative membrane binding.

\section{Apparent $\mathrm{Ca}^{2+}$ Independence}

Syt-7 C2AB bound to membranes containing $\mathrm{PIP}_{2}$ even prior to $\mathrm{Ca}^{2+}$ addition (Figure $1 \mathrm{~B}$ ), and was not reversed by EDTA (Figure S3F). For this reason, we did not measure EDTA-induced dissociation kinetics from liposomes containing $\mathrm{PIP}_{2}$. Thus, it remains unknown whether Syt-7 membrane binding is cooperative in the presence of $\mathrm{PIP}_{2}$, although the $\mathrm{Ca}^{2+}$ and EDTA independence of the $\mathrm{C} 2 \mathrm{AB}$ tandem suggests a strong effect of combining the two domains. In the presence of $\mathrm{PIP}_{2}$, the membrane binding of the Syt-7 C2B domain becomes comparable to or stronger than the C2A domain (Figure 1B), therefore

cooperativity under those conditions would be consistent with the model described above (Figure 6). Membrane bridging and liposome clustering could also contribute to the observed lack of EDTA reversibility for Syt-7 C2AB, but this effect is unlikely to be solely responsible because liposome clustering by other Syt C2 domains is reversed upon EDTA addition $(50,51)$.

The Syt-7 C2AB tandem was also partially membrane-bound prior to $\mathrm{Ca}^{2+}$ addition in the absence of $\mathrm{PIP}_{2}$; however, we interpret this result as arising from extreme sensitivity to sub- 
micromolar levels of $\mathrm{Ca}^{2+}$ in the assay solutions rather than $\mathrm{Ca}^{2+}$ insensitivity, as the $\mathrm{C} 2 \mathrm{AB}$ tandem was effectively removed from PM(-)PIP 2 liposomes upon EDTA addition (Figure S3C). Furthermore, neither individual domain of Syt-7 was observed to have a $\mathrm{Ca}^{2+}$-insensitive component in the absence of $\mathrm{PIP}_{2}$ (Figure 1A). The isolated Syt-7 C2B domain also bound somewhat to $\mathrm{PIP}_{2}$-containing membranes prior to $\mathrm{Ca}^{2+}$ addition (Figure $1 \mathrm{~B}$ ); this result is reminiscent of prior reports of partial $\mathrm{Ca}^{2+}$-independent $\mathrm{PIP}_{2}$ binding by Syt-1 C2B $(28,57)$. This interaction was also reversed by EDTA (Figure S3E), suggesting it may not be truly $\mathrm{Ca}^{2+}$ independent. However, we cannot exclude the possibility of a weak, $\mathrm{Ca}^{2+}$-independent interaction that becomes screened electrostatically by the EDTA polyanion (58).

\section{Liposome Clustering and Aggregation}

Previously, Syt-1 C2B and C2AB as well as Syt-7 C2A and C2AB have been found to induce liposome aggregation $(17,34,50,51)$. In this study, we report that Syt-7 C2B shares the same property using 1:1 DOPC/DOPS liposomes. This contrasts with a previous report which observed little to no aggregation with Syt-7 C2B and 3:1 PC/PS liposomes (17). It is possible that the increased anionic content in our liposomes is sufficient to engage a second binding site in this domain, similar to Syt-1 C2B. Both of the polybasic regions that have been suggested to impact bilayer bridging by Syt-1 C2B are present in Syt-7 C2B as well $(7,29,59)$. As expected, liposome clustering is concentration dependent (Figure S4) $(28,57)$. In these experiments, liposome clustering arising from bilayer bridging may reflect a separate structural state from the co-insertion events whose extent of cooperativity was probed in this study, and therefore we sought to minimize aggregation by choosing conditions that favor co-insertion, such as low protein-to-lipid ratios (36). At higher protein-to-lipid ratios, liposome aggregation appeared to produce or exaggerate a slow component of the kinetic time course (Figure S5; Table S1). However, the rate constant of the major component of the kinetic time course remained unaffected; therefore, we conclude that this rate constant represents dissociation of the proteins from the liposome surface.

\section{Implications for Evolution of Synaptotagmin Function}

Despite their different $\mathrm{Ca}^{2+}$ sensitivities and kinetics, both Syt-1 and Syt-7 insert their $\mathrm{C} 2 \mathrm{~B}$ domain $\mathrm{Ca}^{2+}$-binding loops more deeply into membranes as $\mathrm{C} 2 \mathrm{AB}$ tandems than as individual domains. Our data suggest this insertion leads to interdomain cooperativity in Syt-1 but not Syt-7, at least in the absence of $\mathrm{PIP}_{2}$, presumably because the enhanced $\mathrm{C} 2 \mathrm{~B}$ insertion increases overall membrane binding affinity more strongly for the $\mathrm{C} 2 \mathrm{~B}$-dominated Syt-1 than for the C2A-dominated Syt-7 (Figure 6). The conservation of this structural feature suggests that co-insertion of $\mathrm{C} 2$ domain $\mathrm{Ca}^{2+}$ binding loops into the same membrane may be a common feature among synaptotagmins, even under conditions where some degree of liposome clustering is also present (36). We recently posited that synaptotagmins in the three-dimensional context of a fusion pore could assume a geometry in which the $\mathrm{C} 2 \mathrm{~A}$ and $\mathrm{C} 2 \mathrm{~B} \mathrm{Ca}^{2+}$-binding loops copenetrate the fusion pore neck while the polybasic regions bridge between opposing membranes 
(7). In other words, cooperative membrane insertion and bilayer bridging are not necessarily contradictory functions. In principle, cooperativity between $\mathrm{C} 2$ domains could facilitate rapid and efficient co-insertion to stabilize the fusion pore during a $\mathrm{Ca}^{2+}$ signaling event, while maintaining a low membrane affinity at basal $\mathrm{Ca}^{2+}$ levels. Future studies comparing structural and energetic properties of synaptotagmin isoforms could provide key insights into the evolution of synaptotagmin function in fusion pore formation and stabilization. 
bioRxiv preprint doi: https://doi.org/10.1101/393702; this version posted August 20,2018 . The copyright holder for this preprint (which was not certified by peer review) is the author/funder, who has granted bioRxiv a license to display the preprint in perpetuity. It is made available under aCC-BY-NC-ND 4.0 International license.

\section{Author Contributions}

H.T., L.A., and J.K. designed research; H.T. and L.A. performed research; H.T., L.A., and J.K. analyzed data; H.T. and J.K. wrote the manuscript. 


\section{References}

1. Brose, N., A. G. Petrenko, T. C. Sudhof, and R. Jahn. 1992. Synaptotagmin: a calcium sensor on the synaptic vesicle surface. Science 256:1021-1025.

2. Chapman, E. R. 2008. How does synaptotagmin trigger neurotransmitter release? Annu Rev Biochem 77:615-641.

3. Gustavsson, N., and W. Han. 2009. Calcium-sensing beyond neurotransmitters: functions of synaptotagmins in neuroendocrine and endocrine secretion. Biosci Rep 29:245-259.

4. Bhalla, A., M. C. Chicka, and E. R. Chapman. 2008. Analysis of the synaptotagmin family during reconstituted membrane fusion. Uncovering a class of inhibitory isoforms. J Biol Chem 283:21799-21807.

5. Craxton, M. 2010. A manual collection of Syt, Esyt, Rph3a, Rph3al, Doc2, and Dblc2 genes from 46 metazoan genomes--an open access resource for neuroscience and evolutionary biology. BMC Genomics 11:37.

6. Moghadam, P. K., and M. B. Jackson. 2013. The functional significance of synaptotagmin diversity in neuroendocrine secretion. Front Endocrinol (Lausanne) 4:124.

7. MacDougall, D. D., Z. Lin, N. L. Chon, S. L. Jackman, H. Lin, J. D. Knight, and A. Anantharam. 2018. The high-affinity calcium sensor synaptotagmin-7 serves multiple roles in regulated exocytosis. J Gen Physiol 150:783-807.

8. Fernandez-Chacon, R., A. Konigstorfer, S. H. Gerber, J. Garcia, M. F. Matos, C. F. Stevens, N. Brose, J. Rizo, C. Rosenmund, and T. C. Sudhof. 2001. Synaptotagmin I functions as a calcium regulator of release probability. Nature 410:41-49.

9. Bacaj, T., D. Wu, X. Yang, W. Morishita, P. Zhou, W. Xu, R. C. Malenka, and T. C. Sudhof. 2013. Synaptotagmin-1 and synaptotagmin-7 trigger synchronous and asynchronous phases of neurotransmitter release. Neuron 80:947-959.

10. Liu, H., H. Bai, E. Hui, L. Yang, C. S. Evans, Z. Wang, S. E. Kwon, and E. R. Chapman. 2014. Synaptotagmin 7 functions as a $\mathrm{Ca}^{2+}$-sensor for synaptic vesicle replenishment. eLife 3:e01524.

11. Jackman, S. L., J. Turecek, J. E. Belinsky, and W. G. Regehr. 2016. The calcium sensor synaptotagmin 7 is required for synaptic facilitation. Nature 529:88-91.

12. Li, Y., P. Wang, J. Xu, F. Gorelick, H. Yamazaki, N. Andrews, and G. V. Desir. 2007. Regulation of insulin secretion and GLUT4 trafficking by the calcium sensor synaptotagmin VII. Biochem Biophys Res Commun 362:658-664.

13. Bhalla, A., W. C. Tucker, and E. R. Chapman. 2005. Synaptotagmin isoforms couple distinct ranges of $\mathrm{Ca}^{2+}, \mathrm{Ba}^{2+}$, and $\mathrm{Sr}^{2+}$ concentration to SNARE-mediated membrane fusion. Mol Biol Cell 16:4755-4764.

14. Hui, E., J. Bai, P. Wang, M. Sugimori, R. R. Llinas, and E. R. Chapman. 2005. Three distinct kinetic groupings of the synaptotagmin family: candidate sensors for rapid and delayed exocytosis. Proc Natl Acad Sci US A 102:5210-5214.

15. Brandt, D. S., M. D. Coffman, J. J. Falke, and J. D. Knight. 2012. Hydrophobic contributions to the membrane docking of synaptotagmin $7 \mathrm{C} 2 \mathrm{~A}$ domain: mechanistic contrast between isoforms 1 and 7. Biochemistry 51:7654-7664.

16. Osterberg, J. R., N. L. Chon, A. Boo, F. A. Maynard, H. Lin, and J. D. Knight. 2015. Membrane docking of the synaptotagmin $7 \mathrm{C} 2 \mathrm{~A}$ domain: Electron paramagnetic 
resonance measurements show contributions from two membrane binding loops. Biochemistry 54:5684-5695.

17. Voleti, R., D. R. Tomchick, T. C. Sudhof, and J. Rizo. 2017. Exceptionally tight membrane-binding may explain the key role of the synaptotagmin-7 C2A domain in asynchronous neurotransmitter release. Proc Natl Acad Sci U S A 114:E8518-E8527.

18. Vermaas, J. V., and E. Tajkhorshid. 2017. Differential membrane binding mechanics of synaptotagmin isoforms observed in atomic detail. Biochemistry 56:281-293.

19. Sutton, R. B., B. A. Davletov, A. M. Berghuis, T. C. Sudhof, and S. R. Sprang. 1995. Structure of the first C2 domain of synaptotagmin I: a novel $\mathrm{Ca}^{2+} /$ phospholipid-binding fold. Cell 80:929-938.

20. Fernandez, I., D. Arac, J. Ubach, S. H. Gerber, O. Shin, Y. Gao, R. G. Anderson, T. C. Sudhof, and J. Rizo. 2001. Three-dimensional structure of the synaptotagmin 1 C2Bdomain: synaptotagmin 1 as a phospholipid binding machine. Neuron 32:1057-1069.

21. Zhang, X., J. Rizo, and T. C. Sudhof. 1998. Mechanism of phospholipid binding by the C2A-domain of synaptotagmin I. Biochemistry 37:12395-12403.

22. Bai, J., P. Wang, and E. R. Chapman. 2002. C2A activates a cryptic $\mathrm{Ca}^{2+}$-triggered membrane penetration activity within the C2B domain of synaptotagmin I. Proc Natl Acad Sci U S A 99:1665-1670.

23. Hui, E., J. Bai, and E. R. Chapman. 2006. $\mathrm{Ca}^{2+}$-triggered simultaneous membrane penetration of the tandem C2-domains of synaptotagmin I. Biophys J 91:1767-1777.

24. Herrick, D. Z., W. Kuo, H. Huang, C. D. Schwieters, J. F. Ellena, and D. S. Cafiso. 2009. Solution and membrane-bound conformations of the tandem C2A and C2B domains of synaptotagmin 1: Evidence for bilayer bridging. J Mol Biol 390:913-923.

25. Chon, N. L., J. R. Osterberg, J. Henderson, H. M. Khan, N. Reuter, J. D. Knight, and H. Lin. 2015. Membrane docking of the synaptotagmin 7 C2A domain: Computation reveals interplay between electrostatic and hydrophobic contributions. Biochemistry 54:56965711.

26. Bendahmane, M., K. P. Bohannon, M. M. Bradberry, T. C. Rao, M. W. Schmidtke, P. S. Abbineni, N. L. Chon, S. Tran, H. Lin, E. R. Chapman, J. D. Knight, and A. Anantharam. 2018. The synaptotagmin C2B domain calcium-binding loops modulate the rate of fusion pore expansion. Mol Biol Cell.

27. Bai, J., W. C. Tucker, and E. R. Chapman. 2004. PIP 2 increases the speed of response of synaptotagmin and steers its membrane-penetration activity toward the plasma membrane. Nat Struct Mol Biol 11:36-44.

28. Radhakrishnan, A., A. Stein, R. Jahn, and D. Fasshauer. 2009. The $\mathrm{Ca}^{2+}$ affinity of synaptotagmin 1 is markedly increased by a specific interaction of its $\mathrm{C} 2 \mathrm{~B}$ domain with phosphatidylinositol 4,5-bisphosphate. J Biol Chem 284:25749-25760.

29. Honigmann, A., G. van den Bogaart, E. Iraheta, H. J. Risselada, D. Milovanovic, V. Mueller, S. Mullar, U. Diederichsen, D. Fasshauer, H. Grubmuller, S. W. Hell, C. Eggeling, K. Kuhnel, and R. Jahn. 2013. Phosphatidylinositol 4,5-bisphosphate clusters act as molecular beacons for vesicle recruitment. Nat Struct Mol Biol 20:679-686.

30. Perez-Lara, A., A. Thapa, S. B. Nyenhuis, D. A. Nyenhuis, P. Halder, M. Tietzel, K. Tittmann, D. S. Cafiso, and R. Jahn. 2016. PtdInsP2 and PtdSer cooperate to trap synaptotagmin-1 to the plasma membrane in the presence of calcium. eLife 5. 
31. Mackler, J. M., J. A. Drummond, C. A. Loewen, I. M. Robinson, and N. E. Reist. 2002. The $\mathrm{C} 2 \mathrm{~B} \mathrm{Ca}{ }^{2+}$-binding motif of synaptotagmin is required for synaptic transmission in vivo. Nature 418:340-344.

32. Fernandez-Chacon, R., O. H. Shin, A. Konigstorfer, M. F. Matos, A. C. Meyer, J. Garcia, S. H. Gerber, J. Rizo, T. C. Sudhof, and C. Rosenmund. 2002. Structure/function analysis of $\mathrm{Ca}^{2+}$ binding to the C2A domain of synaptotagmin 1. J Neurosci 22:8438-8446.

33. Segovia, M., E. Ales, M. A. Montes, I. Bonifas, I. Jemal, M. Lindau, A. Maximov, T. C. Sudhof, and G. Alvarez de Toledo. 2010. Push-and-pull regulation of the fusion pore by synaptotagmin-7. Proc Natl Acad Sci U S A 107:19032-19037.

34. Hui, E., J. D. Gaffaney, Z. Wang, C. P. Johnson, C. S. Evans, and E. R. Chapman. 2011. Mechanism and function of synaptotagmin-mediated membrane apposition. Nat Struct Mol Biol 18:813-821.

35. Seven, A. B., K. D. Brewer, L. Shi, Q. X. Jiang, and J. Rizo. 2013. Prevalent mechanism of membrane bridging by synaptotagmin-1. Proc Natl Acad Sci U S A 110:E3243-3252.

36. Vennekate, W., S. Schroder, C. C. Lin, G. van den Bogaart, M. Grunwald, R. Jahn, and P. J. Walla. 2012. Cis- and trans-membrane interactions of synaptotagmin-1. Proc Natl Acad Sci U S A 109:11037-11042.

37. Herrick, D. Z., S. Sterbling, K. A. Rasch, A. Hinderliter, and D. S. Cafiso. 2006. Position of synaptotagmin I at the membrane interface: cooperative interactions of tandem C2 domains. Biochemistry 45:9668-9674.

38. Krishnamurthy, V. M., Estroff, L.A., Whitesides, G.M. 2006. Multivalency in Ligand Design. In Fragment-based Approaches in Drug Discovery. W. Jahnke, Erlanson, D.A., editor. Wiley, New York. 11-54.

39. Takahashi, H., V. Shahin, R. M. Henderson, K. Takeyasu, and J. M. Edwardson. 2010. Interaction of synaptotagmin with lipid bilayers, analyzed by single-molecule force spectroscopy. Biophys J 99:2550-2558.

40. Ma, L., Y. Cai, Y. Li, J. Jiao, Z. Wu, B. O'Shaughnessy, P. De Camilli, E. Karatekin, and Y. Zhang. 2017. Single-molecule force spectroscopy of protein-membrane interactions. eLife 6.

41. Bai, H., R. Xue, H. Bao, L. Zhang, A. Yethiraj, Q. Cui, and E. R. Chapman. 2016. Different states of synaptotagmin regulate evoked versus spontaneous release. Nature communications 7:10971.

42. Vasquez, J. K., K. Chantranuvatana, D. T. Giardina, M. D. Coffman, and J. D. Knight. 2014. Lateral diffusion of proteins on supported lipid bilayers: Additive friction of synaptotagmin 7 C2A-C2B tandem domains. Biochemistry 53:7904-7913.

43. Corbin, J. A., R. A. Dirkx, and J. J. Falke. 2004. GRP1 pleckstrin homology domain: Activation parameters and novel search mechanism for rare target lipid. Biochemistry 43:16161-16173.

44. Joint Proteomics Laboratory of the Ludwig Institute for Cancer Research, Walter and Eliza Hall Institute of Medical Research. 2006. Measuring protein concentration in the presence of nucleic acids by A280/A260: The method of Warburg and Christian. In CSH Protoc. doi:10.1101/pdb.prot4252

45. Golovanov, A. P., G. M. Hautbergue, S. A. Wilson, and L. Y. Lian. 2004. A simple method for improving protein solubility and long-term stability. J Am Chem Soc 126:8933-8939. 
46. Ubach, J., Y. Lao, I. Fernandez, D. Arac, T. C. Sudhof, and J. Rizo. 2001. The C2B domain of synaptotagmin I is a $\mathrm{Ca}^{2+}$-binding module. Biochemistry 40:5854-5860.

47. Nalefski, E. A., M. M. Slazas, and J. J. Falke. 1997. $\mathrm{Ca}^{2+}$-signaling cycle of a membranedocking C2 domain. Biochemistry 36:12011-12018.

48. Nalefski, E. A., and J. J. Falke. 2002. Use of fluorescence resonance energy transfer to monitor $\mathrm{Ca}^{2+}$-triggered membrane docking of C2 domains. Methods Mol Biol 172:295303.

49. Nalefski, E. A., M. A. Wisner, J. Z. Chen, S. R. Sprang, M. Fukuda, K. Mikoshiba, and J. J. Falke. 2001. C2 domains from different $\mathrm{Ca}^{2+}$ signaling pathways display functional and mechanistic diversity. Biochemistry 40:3089-3100.

50. Arac, D., X. Chen, H. A. Khant, J. Ubach, S. J. Ludtke, M. Kikkawa, A. E. Johnson, W. Chiu, T. C. Sudhof, and J. Rizo. 2006. Close membrane-membrane proximity induced by $\mathrm{Ca}^{2+}$-dependent multivalent binding of synaptotagmin-1 to phospholipids. Nat Struct Mol Biol 13:209-217.

51. Hamilton, D. J., M. D. Coffman, J. D. Knight, and S. M. Reed. 2017. Lipid-coated gold nanoparticles and FRET allow sensitive monitoring of liposome clustering mediated by the synaptotagmin-7 C2A domain. Langmuir 33:9222-9230.

52. Frazier, A. A., M. A. Wisner, N. J. Malmberg, K. G. Victor, G. E. Fanucci, E. A. Nalefski, J. J. Falke, and D. S. Cafiso. 2002. Membrane orientation and position of the C2 domain from cPLA 2 by site-directed spin labeling. Biochemistry 41:6282-6292.

53. Kohout, S. C., S. Corbalan-Garcia, J. C. Gomez-Fernandez, and J. J. Falke. 2003. C2 domain of protein kinase $\mathrm{C} \alpha$ : elucidation of the membrane docking surface by sitedirected fluorescence and spin labeling. Biochemistry 42:1254-1265.

54. Frazier, A. A., C. R. Roller, J. J. Havelka, A. Hinderliter, and D. S. Cafiso. 2003. Membrane-bound orientation and position of the synaptotagmin I C2A domain by sitedirected spin labeling. Biochemistry 42:96-105.

55. Rufener, E., A. A. Frazier, C. M. Wieser, A. Hinderliter, and D. S. Cafiso. 2005. Membrane-bound orientation and position of the synaptotagmin C2B domain determined by site-directed spin labeling. Biochemistry 44:18-28.

56. Xue, M., T. K. Craig, O. H. Shin, L. Li, C. A. Brautigam, D. R. Tomchick, T. C. Sudhof, C. Rosenmund, and J. Rizo. 2010. Structural and mutational analysis of functional differentiation between synaptotagmins-1 and -7. PLoS One 5.

57. Tucker, W. C., J. M. Edwardson, J. Bai, H. J. Kim, T. F. Martin, and E. R. Chapman. 2003. Identification of synaptotagmin effectors via acute inhibition of secretion from cracked PC12 cells. J Cell Biol 162:199-209.

58. Park, Y., J. B. Seo, A. Fraind, A. Perez-Lara, H. Yavuz, K. Han, S. R. Jung, I. Kattan, P. J. Walla, M. Choi, D. S. Cafiso, D. S. Koh, and R. Jahn. 2015. Synaptotagmin-1 binds to $\mathrm{PIP}_{2}$-containing membrane but not to SNAREs at physiological ionic strength. Nat Struct Mol Biol 22:815-823.

59. Xue, M., C. Ma, T. K. Craig, C. Rosenmund, and J. Rizo. 2008. The Janus-faced nature of the C2B domain is fundamental for synaptotagmin-1 function. Nat Struct Mol Biol 15:1160-1168. 